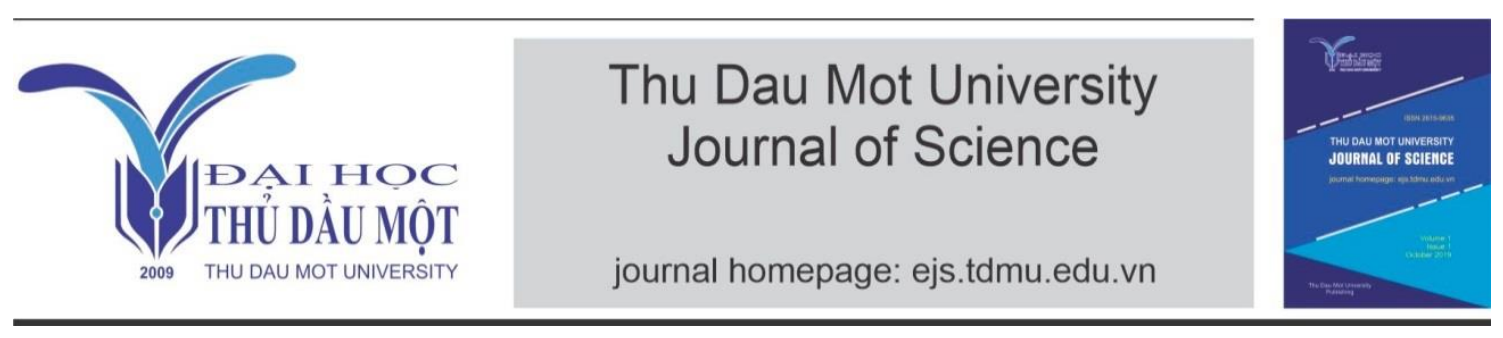

\title{
Design of hand-wash equipment prevention Covid-19 use solar energy
}

by Thanh Tung Nguyen (Thu Dau Mot University, Vietnam)

$\begin{array}{ll}\text { Article Info: } & \text { Received } 20 \text { April 2021, Accepted } 2 \text { June 2021, Available online } 15 \text { June } 2021 \\ & \text { Corresponding author: tungnt@tdmu.edu.vn } \\ & \text { https://doi.org/10.37550/tdmu.EJS/2021.02.196 }\end{array}$

\begin{abstract}
SARSCOV-2 virus and new strains have been spreading in most countries and regions around the world, the COVID-19 epidemic it causes has infected millions of people, the urgent need is to prevent their spread. On the market, there are many types of hand wash equipment automatically spray disinfectant solution used with many different sensors and operating principles, but most are still using AC power. In this topic, we design automatic hand-wash equipment by applying the transmitter and receiver principle of the moving infrared sensor circuit and delay relay circuit to detect someone appearing in the observation area, click activating the MP3 reader circuit plays the 5D (5D-Dodge - Disinfection Distance - Dismeeting - Declare) propaganda sound about Covid -19 disease prevention and the position sensor activates the mini-pump to spray the handwashing gel within a certain detecting distance. We have conducted experiments and completed our projects with devices that use energy from solar cells, through charging circuits and storage batteries to use renewable energy, minimizing the impact of the greenhouse effect.
\end{abstract}

Keywords: automatic hand-wash, solar application, 5D propagation, Covid-19 prevention

\section{Introduction}

Microcontrollers, with electronic circuit systems using sensors in general, have been making an important contribution to the application of science and technology, 
contributing to the economic development around the world. Using microcontrollers brings great benefits in engineering, from the formation of robotic arms in factories that assemble electrical, electronic equipment, automobile assemblies to increase working efficiency many times (Phan Quốc Phô, Nguyễn Đức Chiến, 2006)..

The energy sources that people learn, exploit and use up to now are divided into 2 groups, which are renewable and non-renewable energy. The group of non-renewable energy includes: coal, kerosene, gas, and hydroelectricity are the basic components with a large rate of use in the past to present (Cliff Orori Mosiori, 2016; Lewis Fraas, Larry Partain, 2010).

The group of non-renewable energy has been exploited and used a lot by countries around the world in recent times to serve human needs, up to now has gradually exhausted its reserves and will even run out in the future or in the near future several more decades in some developing countries. On the other hand, when exploiting these energy sources, people will affect the environment of the flora and fauna, for example, it is necessary to dig hundreds of meters deep in the mines to exploit coal, absorb gas, and marine crude oil will affect the geological strata of the continental shelf, marine flora and fauna. With construction of hydroelectric dams requires deforestation, flow prevention, and relocation, affecting the economic and social lives of people who live in these lands or downstream areas.

The group of non-renewable energy also known as green energy includes: solar energy, wind energy, wave energy, tidal energy...

The group of non-renewable energy also known as green energy includes: solar energy, wind energy, wave energy, tides ... Renewable energy group can be considered as an almost endless source of energy (Bill Gates, 2021). In the process of exploiting these types of energy, there will be some impact on the ecological environment, such as wind power will affect birds living in the area, solar panels, when damaged, will accumulate some substances semiconductor, rare earth atoms. However, this pollution is considered insignificant and has not been verified, so it can be considered as the clean energy of the future (Lewis Fraas, Larry Partain, 2010; Marko Batic et al., 2021).

Infrared, also known as infrared, is electromagnetic radiation with wavelength longer than light and shorter than microwave radiation. Infrared means in addition to the red wave. Red is the color with the longest wavelength in visible light. Usually objects above $35^{\circ} \mathrm{C}$ emit infrared wavelength. Infrared radiation was unknowingly discovered by an astronomer named William Herschel in 1800. While measuring the temperature of each color of light scattered by a prism, he noticed that the temperature was beyond the red light is highest.

Infrared sensor (English name is IR sensor), they are an electronic device capable of 
measuring and detecting infrared radiation in the surrounding environment. Actually, the English name of the infrared sensor is Passive Infrared, abbreviated as PIR which literally translates to "passive infrared". The infrared sensor emits rays invisible to the human eye, because its wavelength is longer than visible light (although it remains on the same electromagnetic spectrum) (Sergey Yourich, 2016).

There are two types of infrared sensors that are active and passive sensors. Infrared sensors work by emitting and detecting and receiving infrared radiation.

Active infrared sensors are usually composed of two parts: light-emitting diode (LED) and receiver. When an object approaches the sensor, infrared light from the LED is reflected off the object and detected by the receiver. Infrared sensors act as proximity sensors and they are often used in obstacle detection systems (like in robots).

Passive infrared sensor means only receiving infrared rays emitted from other objects such as humans, animals or any other heat source, by itself does not emit any infrared rays at all. After detecting the source of heat, the sensor will analyze to determine the condition for the alarm signal, so it is called passive (Dương Minh Trí, 2007).

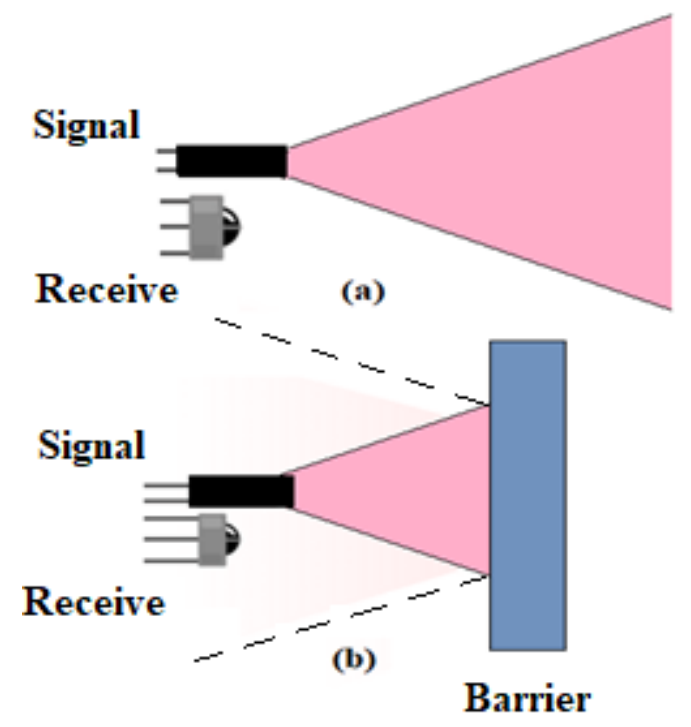

Figure 1. Image showing the transmitting and receiving principle of an infrared sensor;

a) When there are no obstructions; b) When obstructions appear

Hand washing is the best way to keep germs from spreading. Health experts recommend frequent and proper hand washing to prevent the spread of gastrointestinal diseases, acute infections that endanger the respiratory tract such as: SARS, Influenza A (H5N1, H7N9), Hand, foot and mouth disease and respiratory infections caused by the new strain of Coronavirus.

According to scientists, germs exist and multiply everywhere - indoors, on the streets, at home, at work. In particular, the skin of the hands is making a "record" of the number of 
bacteria residing, with 40,000 bacteria on just $1 \mathrm{~cm}^{2}$ of normal human skin.

The germs can get into the body through the air when someone with a respiratory infection coughs or sneezes. The germs can enter the body through our hands when we do not wash our hands, bring the flu germs to our eyes, nose or mouth, and enter the body. They then multiply in the nose, ears, or throat and cause illness.

Hand washing with soap or an antiseptic solution is the best way to remove germs that cause serious illnesses for children such as coughs, flu (acute respiratory infections) and diarrhea. Knowing the possible pathways for germs to enter the body makes it easier for people to set up a protective barrier that prevents germs from moving from hand to mouth to nose. However, for effective prevention, we need to wash our hands at the right time and the right way. Using your hands to touch the same object, such as opening a soap lid can also spread germs and viruses between people.

\section{Experiment}

From the medical professional information as mentioned above, it shows that the design of a system of equipment used to wash hands automatically, without collisions is very necessary in the period where people above The world is working hard to prevent the risk of infection from disease source factors that have not been strictly controlled.

Equipment includes the main components of supplies as follows:

Infrared sensor used to detect approaching people with adjustable distance from 0.5 to $3.5 \mathrm{~m}$.

- MP3 reader circuit, memory card with recording file, speaker power circuit used to play audio clip with contents of epidemic prevention propaganda according to the $5 \mathrm{~K}$ principle of the Ministry of Health

- Proximity sensor, determine the position used to receive signals of people in front of the system with a distance from 0 to $10 \mathrm{~cm}$.

- Control circuit, relay delay function to close the circuit according to preset time

- Mini pump system, antiseptic water bottle.

- The energy supply system includes solar battery, charging circuit, battery, voltage stabilizer $12 \mathrm{v}-5 \mathrm{v}$

Our equipment system consists of 2 main branches, performing 2 independent functions that are group of sound generator circuits and group of hand sanitizer gels spray circuit group. 


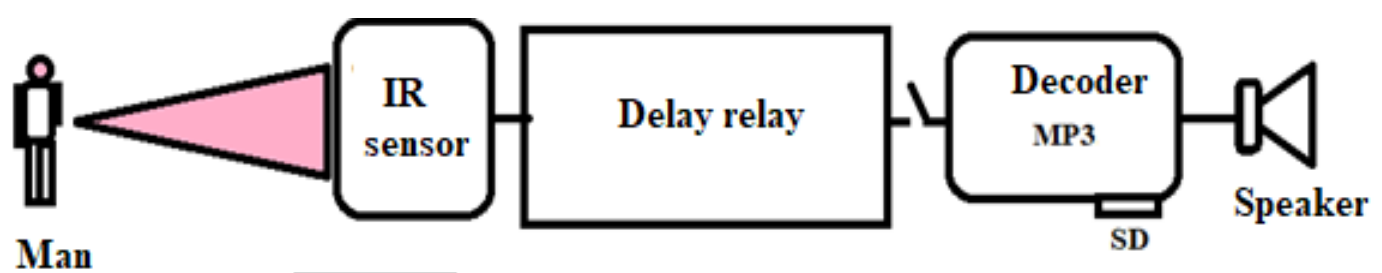

(a)

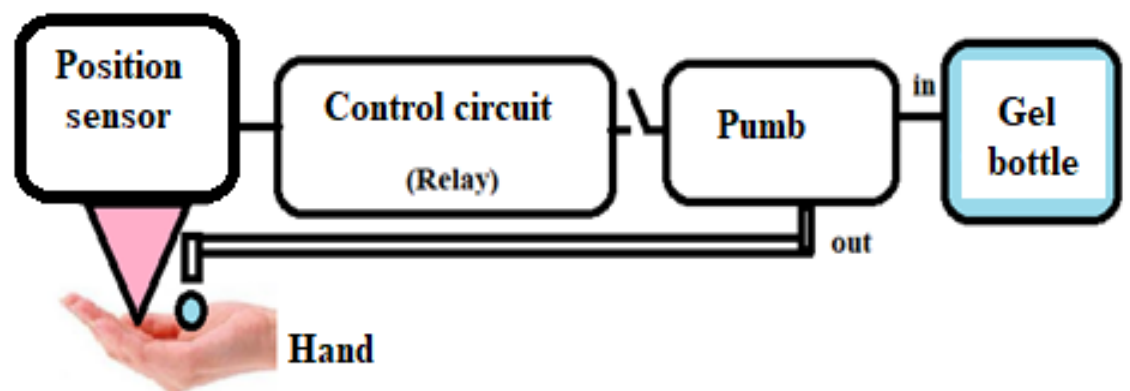

(b)

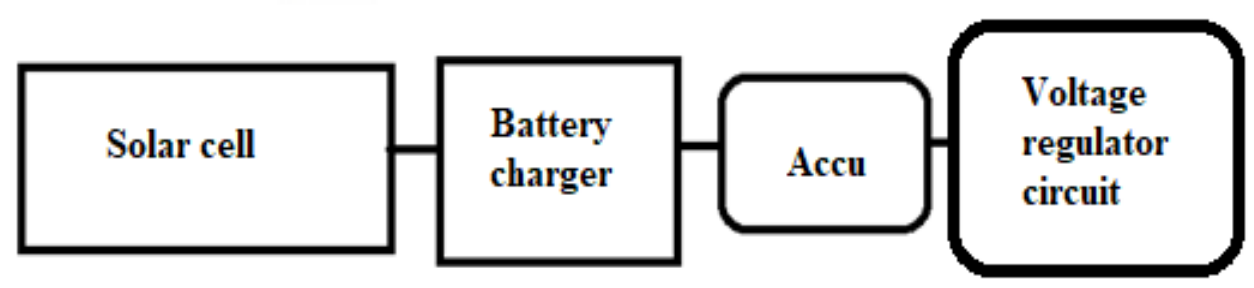

Figure 2. Block diagram of functional parts of equipment (a) sound-generating unit,

(b) antibacterial hand gel spray block, (c) power supply unit

- According to the block diagram of Figure 2a, when someone appears in the space in front of the infrared sensor and is 2 meters away from it, the sensor gives a positive signal activated to the relay module to create a delay, This circuit sets the relay closing command with a delay according to the adjustment of the potentiometer on the module, corresponding to the MP3 decoding circuit being powered and reading the audio file content recorded on the mini SD memory card, emitting sound in speakers. In this study we use the content recorded in the file as the content of propaganda about disease prevention Covid-19 of the Ministry of Health with the slogan "5D".

- For the diagram of Figure 2b, when an obstacle (hand) appears near the position sensor, from $10 \mathrm{~cm}$ back, the sensor receives the reflected signal and compares it with the incoming signal. The same result is a positive voltage at the input at the control circuit, where the active relay closes the circuit for the pump motor, the antibacterial hand sanitizer gel is sprayed into the obstruction position for a time corresponding to the amount of the gel pumped by the motor, which is user-adjustable.

- For the Figure 2c diagram, sunlight is converted to electrical energy through the photovoltaic phenomenon of the solar cell device, the current flows through the charging control circuit and is charged and stored in the battery $12 \mathrm{~V}$ to supply the device.

With the block diagram as shown in Figures $2 a, 2 b, 2 c$ and the principle of operation of 
the device, we proceed to assemble the circuit according to the pin connection diagram Figure 3a, 3b below:
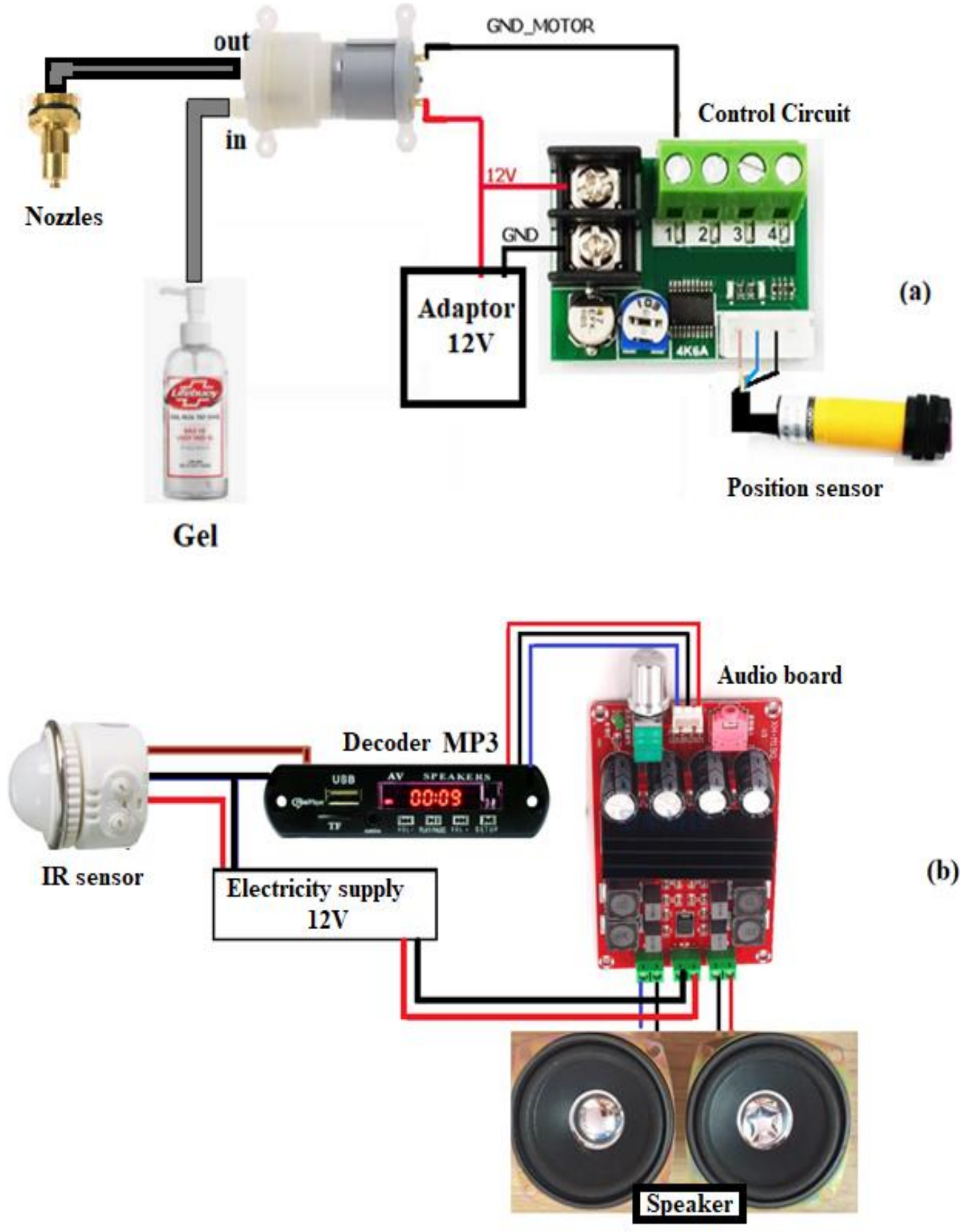

Figure 3. Diagram of wiring between components of equipment; a) Group of control circuits hand-wash gel water spray; b) Group of control circuits that produce sound 
The project we have implemented is aimed at applying to the people in Thanh Hoi Commune, Tan Uyen town, Binh Duong province, Vietnam also known as Turtle Island (due to the image of the islet with features like a turtle), with Method of scientific research in the direction of Transdisciplinarity, has its own characteristics. With the research method in the direction of Transdisciplinarity, the projects products will be oriented to have a clear beneficiary, the target of the project to serve at the request of the beneficiary, the comments of stakeholders. Important is necessary and has a weight equivalent to the idea of the topic owner. For this reason, our hand wash products were conceived with the concept of a tortoise made from ceramic (terracotta), carefully designed to honor the spiritual value of this animal follows local traditions.

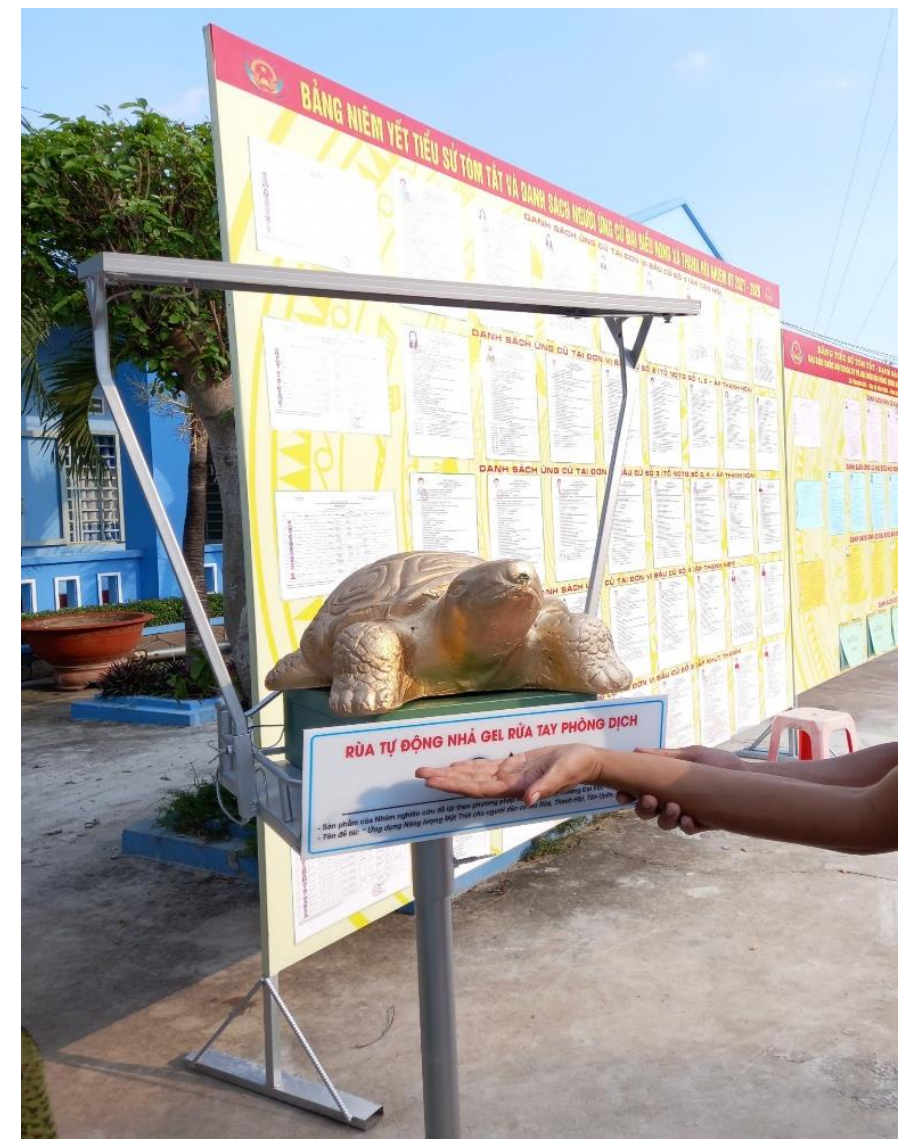

Figure 4. Pictures of turtles releasing hand sanitizer gel Covid-19

\section{Conclusion}

Through the product results that we have achieved, the product of the spraying turtle for hand washing for epidemic prevention has been and is making a great contribution to the ongoing implementation of sanitation, epidemic prevention and disease prevention Covid-19 complicated by the Government's policy and the guidance of the Ministry of 
Health about "5D" in the new rural commune of Thanh Hoi, Binh Duong province, Vietnam. The product is cheap, can be easily installed at the entrance gates of offices, factories, schools and hospitals easy to move to serve the community in the geographical areas and conditions in order to serve the prevention of the spread of epidemics in the current situation.

\section{References}

Bill Gates (2021). How to avoid a climate disaster - The solution we have and Breakthroughs we need, The Top 20 Most Sold \& Most Read Books of the Week, Amazon Charts.

Cliff Orori Mosiori B.Ed (2016). The Solar cell-Solar Cell Technology, Department of Electrical \& Electronic Engineering Rift Valley Insititute of Science and technology, B.O.Box, 7182-20100, Nakuru, Kenya.

Dương Minh Trí (2007). Cảm biến và ưng dụng. NXB Khoa học và Kỹ thuật.

Lewis Fraas, Larry Partain (2010). Solar cells and their applications, Wiley series in Microwave and Optical engineering, Published by John Wiley \& Sons, Inc., New Jersey, Canada.

Marko Batic, Mladen Stanojevic, Sanja Vranes (2021). Renewable Energy Technologies: Simulation and Economic Evaluation, Springer.

Medicine National Academies of Sciences, Engineering, Division on Earth and Life Studies, Board on Life Sciences, Health and Medicine Division (2020), Genomic Epidemiology Data Infrastructure Needs for SARS-CoV-2: Modernizing Pandemic Response Strategies, Consensus study report, The National Academies of Sciences Engineering Medicine

Phan Quốc Phô, Nguyễn Đức Chiến (2006). Giáo trình cảm biến, NXB Khoa học và Kỹ thuật.

Sergey Y.Yourich (2016). Sensors and applications in measuring and automation and control systems, Book Series: Advances in Sensors, IFSA Publishing, Vol. 4.

http://baobinhduong.vn/am-long-tu-tu-rau-nghia-tinh-a242213.html

https://baophapluat.vn/dan-sinh/atm-rau-1000-dong-lam-am-long-nguoi-lao-dong571847.html

http://dienmattroi.asia/about/gioi-thieu-ve-nganh-dien-nang-luong-mat-troi.html

https://tamanhhospital.vn/rua-tay-dung-cach-moi-phong-duoc-benh-dich/ 